\title{
Formula Latihan Teknik Tangan Kanan dalam Gitar Klasik: Shearer, Parkening, dan Werner
}

\author{
Birul Walidaini \\ Jurusan Pendidikan Musik, Fakultas Bahasa dan Seni, Universitas Negeri Yogyakarta \\ E-mail: birul@uny.ac.id
}

\begin{abstract}
Classical guitar developed until now. Aspects and the surrounding area have also experienced developments such as the creation of new compositions, innovation in guitar construction, and the holding of performances that accommodate classical guitar. However, the author tries to raise another area that is quite important in learning classical guitar, namely the teaching method. Along with the development of the times and technology, the basic methods of learning classical guitar are becoming less attention. This article aims to dissect the most basic classical guitar methods and are limited to techniques and instructions for the right hand. This research is a descriptive study with a qualitative design and the classical guitar method book document as an object. The objects raised are the classic Classic Guitar Technique from Aaron Shearer (1963), The Christoper Parkening Guitar Method, Vol. 1 (1997), and the Classical Guitar Method from Bradford Werner (2017). The results of this study present the formula of each method offered to train the right hand in playing classical guitar in their own way. In closing, the authors hope that the classical guitar method remains the basis for learning classical guitar and is further developed in the future.
\end{abstract}

Keywords: classical guitar, right hand, classical guitar method

\begin{abstract}
Abstrak: Gitar klasik telah mengalami perkembangan pesat hingga saat ini. Aspek dan wilayak disekitarnya pun juga ikut mengalami perkembangan seperti terciptanya komposisi-komposisi baru, inovasi konstruksi gitar, maupun terselenggaranya pagelaran-pagelaran yang mewadahi gitar klasik. Namun, penulis mencoba mengangkat wilayah lain yang cukup penting dalam pembelajaran gitar klasik yaitu metode dalam pengajarannya. Seiring berkembanganya zaman dan teknologi metode dasar dalam pembelajaran gitar klasik menjadi kurang diperhatikan. Artikel ini bertujuan untuk membedah metode gitar klasik yang paling mendasar dan dibatasi pada teknik dan instruksi untuk tangan kanan. Penelitian ini merupakan penelitian deskripsif dengan desain kualitatif dan dokumen buku metode gitar klasik sebagai objek. Objek yang diangkat adalah klasik Classic Guitar Technique dari Aaron Shearer (1963), The Christoper Parkening Guitar Method, Vol.1 (1997), dan Classical Guitar Method dari Bradford Werner (2017). Hasil dari penelitian ini menyajikan formula dari setiap metode yang ditawarkan untuk melatih tangan kanan dalam bermain gitar klasik dengan caranya masing-masing. Sebagai penutup penulis berharap agar metode gitar klasik tetap menjadi dasar dalam pembelajaran gitar klasik dan semakin dikembangkan untuk ke depannya.
\end{abstract}

Kata Kunci: gitar klasik, tangan kanan, metode gitar klasik

\section{PENDAHULUAN}

Gitar dianggap sebagai alat musik petik yang umum dan mudah dijumpai hingga saat ini menempati posisi penting dalam bidang ilmu musik barat. Banyak perguruan tinggi dan lembaga pendidikan menawarkan program gitar klasik secara akademik. Hal ini senada dengan apa yang dikemukakan Nabila (2018: 32) Gitar merupakan alat musik yang populer dan gitar begitu cepat berevolusi dari masa ke masa yang menjadikan gitar mempunyai banyak jenis, salah satunya adalah gitar klasik. Kemudian, Miftahunnajah dkk (2013) menyatakan bahwa Gitar merupakan salah satu alat musik yang populer di kalangan masyarakat dunia. Alat musik ini tidak hanya dimainkan oleh masyarakat kelas atas saja, tetapi hampir semua kalangan biasa memainkan salah satu alat musik berdawai ini. Ada beberapa faktor yang mendasari perkembangan gitar klasik menjadi begitu pesat. Pertama, banyak komponis abad dua puluh yang memberikan karya baru seperti Roland Dyens, Leo Brouwer, Joaquin Rodrigo, Carlo Domeniconi. Para komponis tersebut membawa warna baru pada gaya musik mereka, sehingga membuat para pelaku gitar klasik merasa ada penyegaran dalam pemilihan repertoar untuk dimainkan. Repertoar dari komponis abad dua puluh ini memang patut untuk diberi perhatian khusus karena lahir dari 
pikiran baru dan membawa gagasan tersendiri sesuai latar belakang dan budaya mereka masing- masing, bahkan mereka tidak ragu untuk mengenalkan warna tradisional dari negara atau benua mereka masing- masing. Tentu saja hal ini memenuhi harapan para pelaku gitar klasik akan pilihan repertoar yang dianggap jenuh dan kurang bervariasi. Seperti dinyatakan Nabila (2018:33) Terutama pada abad 20 dan 21 dimana banyak karya dari para komponis besar untuk instrument gitar klasik seperti Joaquin Rodrigo, Britten, Carlo Dominiconi, Francis Kleyjans, Roland Dyens dan Leo Brouwer yang memberikan banyak perubahan besar dalam ruang permainan gitar klasik lewat karya-karyanya yang mempunyai karakter yang khas. Kedua, keberanian para pembuat gitar (luthier) dalam mengeksplorasi dan melakukan percobaan terhadap konstruksi gitar klasik itu sendiri, dimana sampai saat ini banyak model variasi yang di bangun oleh para luthier untuk para pemain gitar agar merasa tercukupi kebutuhan bermain gitarnya. Seperti diungkapkan Sloane (1976:11) yang menyatakan bahwa pembuat instrumen mendirikan toko pada akhir abad ketiga belas dan pembuatan instrumen (luthier) adalah seni yang bagus di Andalusia. Luthier Moorish memulai tradisi panjang yang berpuncak pada kemenangan Antonio de Torres Juardo pada pertengahan abad kesembilan belas. Lebih lanjut lagi Sloane (1967) menerangkan bahwa Torres, seorang tukang kayu Spanyol yang awalnya tidak terkenal, menjadi tertarik dengan kemungkinan tonal gitar. Eksperimennya menghasilkan inovasi penting yang memberikan kecemerlangan dan kekuatan yang belum pernah terjadi sebelumnya pada gitar.

Gitar klasik sebagai salah satu pilihan alat musik mempunyai tempat tersendiri dikalangan para pelaku dan penikmat musik. Seperti diungkapkan Salman (2019) bahwa gitar merupakan instrumen musik yang populer dan umum dijumpai di dunia. Hal ini ditunjukan dengan penikmat instrumen gitar mulai dari kalangan atas hingga kalangan bawah. Seperti kebanyakan musik klasik pada umumnya, bahwa untuk memahami atau memainkan repertoar klasik diperlukan tahapan- tahapan dan ketelitian untuk mematuhi aturan yang ada didalamnya. Oleh karena itu, proses pembelajaran musik klasik dalam hal ini dikususkan pada gitar klasik harus melalui lembaga resmi baik sekolah, perguruan tinggi, ataupun lembaga pendidikan musik yang bersifat luar sekolah/private school untuk mencapai sebuah tujuan yaitu menghasilkan sumber daya manusia di bidang gitar klasik yang terdidik secara akademis dan melalui tahap pembelajaran berdasarkan program dan kurikulum musik yang jelas. Sumber daya manusia dibidang gitar klasik yang dimaksud adalah mereka yang mengambil studi musik dan memilih spesialisasi gitar klasik. yang diharapkan dapat berperan dalam aktivitas bermusik khususnya gitar klasik.

Salah satu aktivitas bermusik ialah pementasan, dalam konteks gitar klasik yang dimaksud adalah pementasan dengan memainkan alat musik gitar dan membawakan repertoar standar untuk gitar klasik. pementasan sendiri merupakan sebuah hasil pembelajaran dan latihan yang dilakukan secara berkala dan rutin. Seperti yang diungkapkan (Thompson: 2007) bahwa "pertunjukan musik adalah aktivitas sosial dimana pendengar damat melihat pemain dan sebaliknya" namun, seorang penampil tidak bisa begitu saja menampilkan sebuah repertoar gitar klasik dengan baik jika penampil itu menampilkan repertoar secara tibatiba tanpa adanya proses perbelajaran dan latihan yang jelas dan terstruktur. Pementasan sendiri bersifat komunikatif yang artinya keberhasilan sebuah pementasan adalah terjalinnya komunikasi antara penampil dan audience, sementara proses komunikasi bisa dikatakan berhasil apabila pesan yang disampaikan oleh penampil bisa ditangkap atau dinikmati oleh audience.

Berangkat dari penjabaran diatas penulis mencoba menangkap sisi lain yang tidak kalah menarik daripada perkembangan karya musik, konstruksi gitar maupun kemasan pementasan. Sisi menarik itu adalah perkembangan metode dalam pembelajaran gitar klasik itu sendiri. Sembiring (2018) menyatakan bahwa gitar merupakan sebuah alat musik berdawai yang dimainkan dengan cara dipetik, umumnya menggunakan jari maupun plektrum. Gitar terbentuk atas sebuah bagian tubuh pokok dengan bagian leher yang padat sebagai tempat senar yang umumnya berjumlah enam dirapatkan. Peneliti sepakat dengan pernyataan di atas dan menyimpulkan bahwa gitar klasik menjadi menarik untuk dipentaskan karena ada proses dan tahapan yang harus dilalui, dalam perkembangannya para pelaku gitar klasik lahir dari bimbingan guru atau ahli gitar yang mentransformasikan pengetahuan melalui metode gitar klasik sehingga dapat dikatakan bahwa gitar klasik akan susah, jika dipelajari 
sendiri tanpa adanya pendampingan dari guru, instruktur atau ahli. Penulis merasa bahwa ditengah ramai dan munculnya repertoar baru, konstruksi gitar baru, dan macam-macam gelaran pementasan ada permasalahan yang sedikit terlupakan yaitu metode gitar klasik itu sendiri. Penulis beranggapan metode gitar klasik perlu diperhatikan kembali mengingat jumlahnya yang terbatas dan banyak dilupakan.

Dalam tulisan singkat ini penulis mengangkat dan mengurai tentang metodemetode gitar klasik yang telah disusun oleh para ahli untuk mengingatkan bahwa dalam mempelajari gitar klasik diperlukan pondasi dasar yang kuat dengan melalui tahapantahapan yang telah tersusun dalam sebuah metode. Metode yang akan dibahas adalah Classi Guitar Technique dari Aaron Shearer (1963), The Christoper Parkening Guitar Method, Vol.1 (1997), dan Classical Guitar Method dari Bradford Werner (2017). Pada ketiga buku metode gitar klasik tersebut tahapan dalam mempelajari gitar klasik telah dibahas dan disusun dengan terstruktur agar pelaku atau peminat gitar klasik dapat mempelajari gitar klasik secara bertahap. Tahapan dan pembagian porsi pembelajarannya salah satunya adalah pembagian proses tahapan antara tangan kanan dan kiri. Dalam tulisan ini penulis akan memfokuskan pembahasan pada bagian tangan kanan karena posisi tangan kanan merupakan dasar dalam bermain gitar klasik dan bagi masyarakat umum posisi tangan kanan dapat menjadi indikator ciri khas dari permainan gitar klasik dengan menggunakan empat jari yaitu ibu jari/pulgar, telunjuk/ indiche, jari tengah/medio, jari manis/anular. Sementara dalam permainan gitar non klasik posisi tangan kanan cenderung bebas.

\section{Musik dan Gitar Klasik}

Sejak zaman prasejarah musik telah dianggap sebagai media ekspresi dari perilaku manusia dengan etos yang begitu kuat sehingga dapat memengaruhi emosi, perilaku, dan bahkan moral. Menurut Aristoteles dalam bukunya yang berjudul Doktrin Imitasi, dia berpendapat "bahwa musik meniru keadaan jiwa (kelembutan, kemarahan, keberanian, kesederhanaan, dan kebalikannya)" (Thompson: 2007). Hubungan antara pemain musik dan pengamat ini bukan kebetulan karena mereka memiliki keterkaitan sebagai satu kesatuan dalam sebuah pertunjukan musik. Musik juga bisa disebut sebagai konstruksi dari sistem yang memiliki keterkaitan antara komponen di dalamnya. Dengan demikian, musik memiliki ruang tersendiri dalam kehidupan masyarakat sebagai bentuk komunikasi alami yang terjalin erat dengan seluruh dunia dan kegiatan manusia.

Musik sebagai pengalaman visual dan auditori menjadi satu-satunya cara dimana musik dapat dinikmati secara utuh. Para penikmat musik yang datang untuk menonton pertunjukan musik mendapatkan pengalaman tersendiri dimana para penonton dapat melihat secara langsung keahlian pemain musik dalam mengolah ketrampilan dalam karya yang dimainkan. Saat itulah terjadi komunikasi antara pemain musik dan penonton dalam sebuah pementasan musik.

Pendidikan musik yang di dalamnya memuat salah satu instrumen gitar klasik telah menjadi pilihan tersendiri dalam perkembangannya. Sebagai salah satu disiplin ilmu yang menjadi pilihan dalam belajar, pembelajaran gitar klasik juga dilandasi teoriteori tentang pembelajaran, seperti yang diungkapkan (Parkening 1972:5) yang menyatakan bahwa pembelajaran dirancang untuk menyajikan Metode logis dan sistematis untuk pengembangan musik dan secara teknik bertahap menuju pada tujuan akhir yaitu penguasaan atas instrumen yang agung dan mulia ini. Pendapat di atas menunjukkan bahwa dalam proses penguasaan instrumen musik diperlukan proses yang sistematis.

Grossman (1963: 142) menyatakan bahwa gitar klasik seharusnya digunakan sepenuhnya dalam program musik sekolah bersama dengan alat instrumen orkestra dan band instrumen yang sekarang sedang diajarkan pada sekolah. Lebih lanjut Grossman menambahkan (1963:140) bahwa semakin populernya gitar klasik tidak hanya di kalangan mahasiswa tetapi juga di kalangan anak muda yang pada umumnya gitar klasik memiliki arti penting bagi musik pendidikan. Sebagai alat musik yang berkedudukan sebagai instrumen solo, namun grossman menyatakan kontribusi gitar juga paling efektif dan sensitif sebagai iringan untuk bernyanyi.

Shearer mengutarakan kekhawatiran dan kecemasannya terhadap gitar klasik sebagaimana dia katakan (Shearer 1971: 53) Fakta bahwa gitar secara luas telah disalah pahami menimbulkan beberapa pertanyaan: Mengapa Apakah gitar sudah lama diabaikan? Mengapa begitu sedikit yang diakui sebagai gitaris konser? Dan Shearer dalam tulisan yang sama juga memberikan jawaban akan 
pertanyaannya dan menawarkan saran praktis: Tidak ada instrumen yang diterima secara luas dengan serius sampai pemain master menunjukkan untuk publik nilai estetika yang melekat dan kemungkinan teknis, dan sampai sistem pengajaran logis telah dirumuskan untuk mengajar orang lain untuk bermain instrumen. Diperlukan studi untuk merumuskan prosedur pengajaran yang bermanfaat yang pada gilirannya membantu meningkatkan tingkat kinerja dan memberikan ruang lingkup yang lebih luas dimana komposer dapat bekerja.

Instruksi Umum dalam bermain gitar klasik telah dikemukakan Carl Fischer dalam buku Carcassi Guitar Method (1946:9) yang didalamnya tertulis: Cara memegang dan mengatur posisi. Gitar memiliki enam senar. tiga yang pertama adalah nilon dan yang lainnya ditutupi dengan yang ketiga di bawah yang kedua. nada sebenarnya dari gitar adalah satu oktaf di bawah notasinya. Untuk memegang gitar dengan baik maka perlu duduk sedikit lebih tinggi dari biasanya. kaki kiri harus bertumpu pada bangku yang tingginya proporsional dengan tempat duduk. tempatkan kaki kanan ke depan, tarik sedikit kaki ke belakang. kaki kiri harus mempertahankan posisi aslinya, dan berat instrumen harus bertumpu pada paha kiri, dimana gitar ditempatkan melintang.

Tangan dan lengan kiri. tangan kiri harus menekan leher dengan lembut di antara thumb dan telunjuk. ujung ibu jari harus bertumpu pada sisi di samping senar keenam. Tangan dan lengan kanan. Lengan bawah kanan harus bertumpu pada tepi yang dibentuk oleh sisi instrumen dan papan suara, searah dengan jembatan.

\section{METODE}

Penelitian ini merupakan penelitian deskripsif dengan desain kualitatif dimana dokumen buku metode gitar klasik sebagai objek, upaya yang dilakukan terhadap objek adalah analisis konten dengan maksud ingin membedah lebih dalam isi dari metode gitar klasik yang diambil fokus pada bagian tangan kanan. Teknik analisis dalam penelitian ini adalah melakukan dengan analisis deskriptif terhadap tiga buku metode gitar klasik Classic Guitar Technique dari Aaron Shearer (1963), The Christoper Parkening Guitar Method, Vol.1 (1997), dan Classical Guitar Method dari Bradford Werner (2017). Seperti diungkapkan Abdul Aziz dan Rahayu (2014:3) bahwa pengolahan data deskriptif yaitu dengan menjelaskan suatu permasalahan, gejala atau kejadian sebagaimana adanya, dan bukan menguji kebenaran hipotesis. Kejadian atau fenomena berasal dari bahasa Yunani yaitu "pahainomenon" yang berarti gejala. Menurut Littlejohn (2013) dalam Hasbiansyah (2008:166) fenomenologi merupakan sebuah studi tentang pengetahuan yang bersifat kesadaran memahami dan mengalami sendiri suatu peristiwa atau objek. Artinya, fenomena adalah penampakan suatu peristiwa, realitas, atau keadaan yang ada dalam objek kesadaran manusia. Selanjutnya menurut Creswell (2010:264), penelitian kualitatif adalah metode yang dapat digunakan untuk mengeksplorasi dan memahami makna yang dialami oleh individu dan kelompok dari sebuah permasalahan yang berhubungan dengan sosial dan kemanusiaan.

Pengambilan data dalam penelitian ini dilakukan dengan teknik observasi dimana peneliti melakukan pengamatan seksama terhadap metode gitar klasik Classic Guitar Technique dari Aaron Shearer (1963), The Christoper Parkening Guitar Method, Vol.1 (1997), dan Classical Guitar Method dari Bradford Werner (2017). Kegiatan pengambilan data ini bertujuan agar peneliti mendapatkan pengalaman langsung dan menyelami isi dari objek penelitian dan menghasilkan catatan dan temuan tentang aspek- aspek metode tangan kanan yang ada dalam objek penelitian.

Dalam proses analisis data, peneliti melakukan penyajian data- data yang diperoleh dari objek penelitian selama tahap observasi dan kemudian menyajikannya kedalam items sesuai konten yang didapat dari objek penelitian. Dalam proses analisis ini, peneliti juga melakukan penyaringan terhadap data atau reduksi data terhadap data kurang berkaitan dengan fokus penelitian yaitu metode tangan kanan dalam gitar klasik.

Tahap selanjutnya adalah penyajian data dimana peneliti telah mendapatkan data sesuai yang diharapkan yang bersumber dari objek penelitian yaitu buku metode gitar klasik Classic Guitar Technique dari Aaron Shearer (1963), The Christoper Parkening Guitar Method, Vol.1 (1997), dan Classical Guitar Method dari Bradford Werner (2017). Tahap selanjutnya adalah simpulan data. Dimana peneliti menyimpulkan temuan yang didapat dari objek penelitian buku metode gitar klasik Classic Guitar Technique dari Aaron Shearer (1963), The Christoper Parkening Guitar Method, Vol.1 (1997), dan Classical Guitar Method dari 
Bradford Werner (2017) dengan berlandaskan pada teori dan referensi yang mendukung.

\section{HASIL DAN PEMBAHASAN}

Dari penelusuran terhadap sumber pustaka Classic Guitar Technique dari Aaron Shearer (1963), The Christoper Parkening Guitar Method, Vol.1 (1997), dan Classical Guitar Method dari Bradford Werner (2017) menghasilkan temuan berupa:

\section{Classic Guitar Technique dari Aaron Shearer}

Classic Guitar Technique dari Aaron Shearer (1963) memberikan penjelasan tentang tangan kanan dan contoh pola latihan untuk tangan kanan. Dalam penjelasannya disebutkan bahwa: Tangan kanan; Bagian ini sangat penting, ibu jari dan jari tangan kanan bertanggung jawab untuk membunyikan nada dengan akurat dan cepat, serta menghasilkan corak nada yang berbeda dengan tingkat volume yang berbeda-beda.

Harus dipahami bahwa memainkan alat musik bukanlah proses yang sepenuhnya alami untuk otot yang terlibat. Ini terutama berlaku untuk tangan kanan dalam memainkan gitar. pertama, tangan harus ditempatkan pada posisi yang pada akhirnya akan memberikan hasil yang diinginkan dengan akurasi, kecepatan, dan kontrol nada dan volume yang maksimal; jarijari kemudian dilatih untuk bertindak dengan cara yang paling alami untuk mendapatkan hasil ini.

Penempatan tangan kanan harus dijaga agar tidak mengenai senar, penempatan tangan kanan yang disarankan untuk pemula yaitu: (1) Letakkan lengan bawah kanan secara horizontal ke lantai, sehingga tangan jatuh tepat di belakang lubang suara; (2) Pergelangan tangan dirilekskan dalam kenyamanan kurva ke samping karena konformasi pergelangan tangan akan memungkinkan; (3) pergelangan tangan cukup rata atau tidak pernah lebih melengkung sesuai dengan kecenderungan atau karakteristik individu; (4) Ujung ibu jari dalam keadaan rileks dan bertumpu pada tali sebagai penyangga tangan atau digantung pada tali sebagai penyangga tangan atau digantung ke bawah dalam posisi normal tidak menyentuh senar, mana yang lebih nyaman; serta (5) Jaga bahu tetap rileks, dan umumnya pada bidang horizontal. guarg terhadap kecenderungan bahu kanan terjatuh, menyebabkan lengan menyilang tepi gitar terlalu jauh ke belakang bridge.

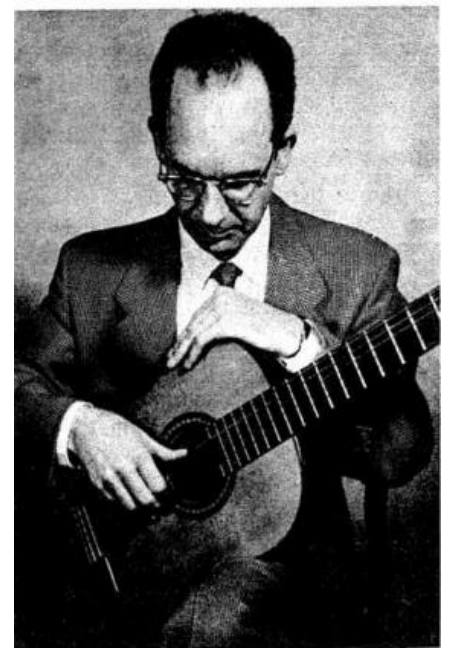

Gambar 1. Placing the Right Hand dari Aaron Shearer

Selain penjelasan buku Classic Guitar Technique dari Aaron Shearer (1963) juga memberikan contoh latihan sebanyak delapan jenis latihan untuk tangan kanan

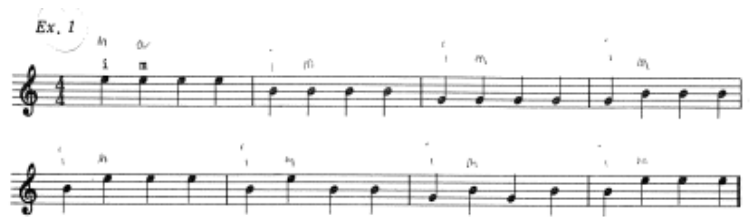

Gambar 2. Classic Guitar Technique dari Aaron Shearer

The Christoper Parkening Guitar Method, Vol. 1

Dalam buku The Christoper Parkening Guitar Method, Vol.1 (1997) diberikan sembilan study atau sembilan jenis latihan salah satunya

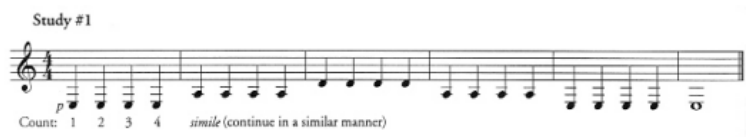

Gambar 3. Study \#1 The Christoper Parkening Guitar Method, Vol. 1

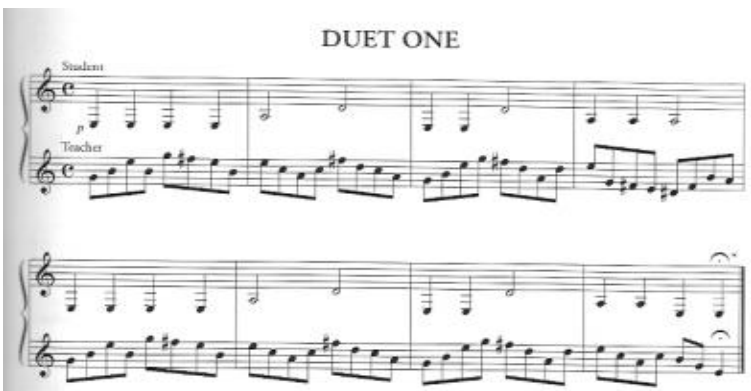

Gambar 4. Duet One The Christoper Parkening Guitar Method, Vol. 1 


\section{Birul Walidaini}

Formula Latihan Teknik Tangan Kanan dalam Gitar Klasik: Shearer, Parkening, dan Werner

Dalam buku The Christoper Parkening Guitar Method, Vol.1 (1997) ini metode latihan yang diberikan tidak hanya untuk murid, namun ada beberapa bagian dimana guru dan murid bermain secara bersama-sama.

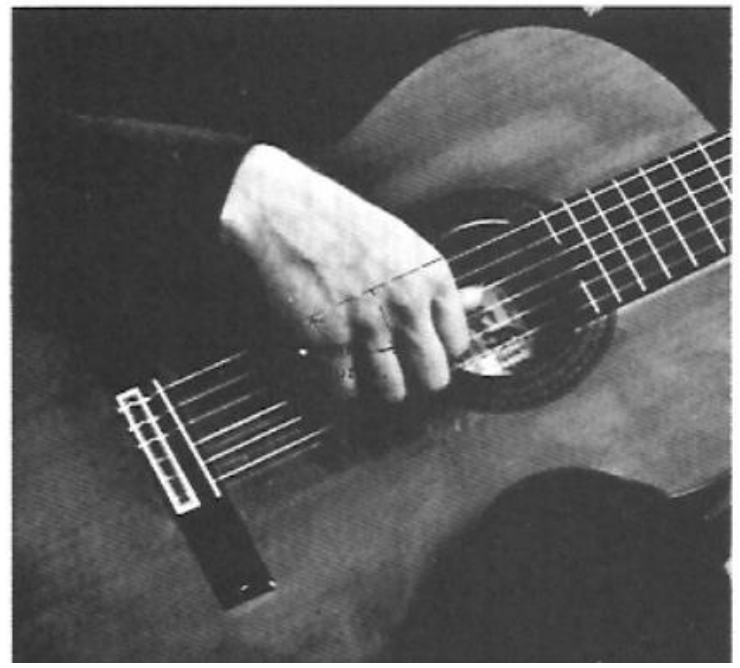

Gambar 5. The Right hand is placed toward the lower end of the sound hole dari Christoper Parkening

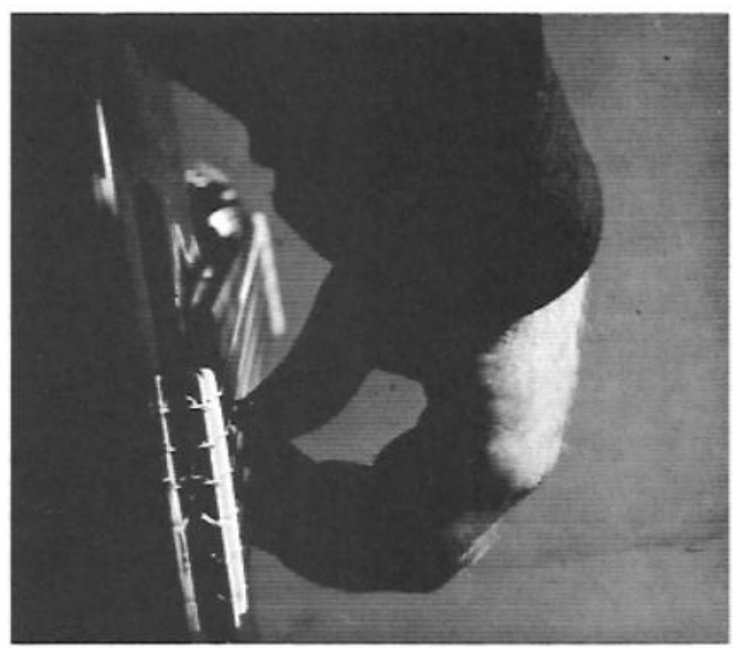

Gambar 6. From the right (Christoper Parkening)

\section{Classical Guitar Method dari Bradford Werner}

Dalam buku Classical Guitar Method dari Bradford Werner (2017) ditemukan penjelasan dan pola latihan yang ditujukan untuk tangan kanan yaitu: Lengan dan Tangan Kanan, meliputi: (1) Lengan bawah kanan bertumpu pada gitar di depan siku; (2) Pergelangan tangan kanan lurus dengan lengkungan yang rileks; (3) Tangan kanan memainkan roset; (4) Jari tangan kanan bergerak ke telapak tangan, bukan ke atas dan ke luar; serta (5) Jempol tangan kanan ada di depan jari.

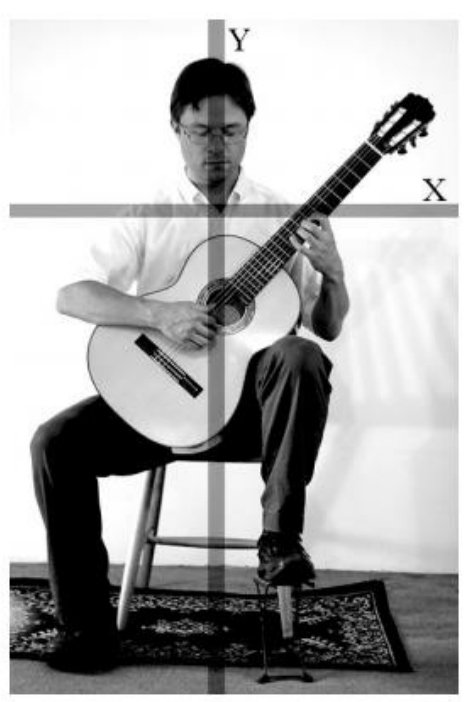

Gambar 7. Postur (Bradford Werner)

Kemudian dalam buku ini juga memberikan sepuluh pola latihan untuk tangan kanan:

Right Hand Technique Exercises

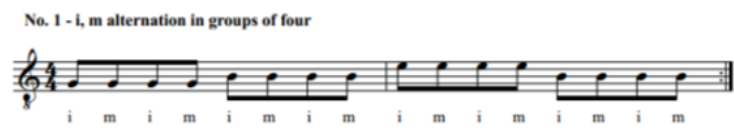

Gambar 8. No.1 Classical Guitar Method dari Bradford Werner

\section{Pembahasan}

Dari penjabaran konten yang didapat dari tiga buku metode gitar klasik di atas dapat kita lakukan pembahasan bahwa metode pembelajaran gitar klasik untuk tangan kanan merupakan bagian penting dalam proses pembelajaran gitar klasik. Seorang murid atau peminat gitar klasik akan sulit juga belajar sendiri tanpa ditemani guru, instruktur atau ahli. Kita dapat melihat perbedaan dari setiap metode yang ditawarkan dimana metode pertama dari Classic Guitar Technique dari Aaron Shearer (1963) banyak memberikan penjelasan mendasar dan instruksional sebelum melakukan praktik. Metode dari Arron Shearer ini memberikan contoh sederhana dan diiringi instruksi yang cukup jelas dan rinci. Kemudian, metode dari Aaron Shearer ini dalam praktiknya disusun dengan tahapan yang jelas dan detail, murid melatih tangan kanan dengan melakukan petikan yang dibagi menjadi dua jenis yaitu petikan senar 1,2,3 dan bagian kedua petikan pada senar 4,5,6. Kemudian pada bagian akhir latihan disusun dengan mengkombinasikan keduanya. 
Metode untuk tangan kanan yang ditawarkan oleh The Christoper Parkening Guitar Method, Vol.1 (1997) menyajikan penjelasan yang tidak terlalu banyak namun dengan porsi praktik yang cukup tinggi. Pada latihan praktik dalam buku The Christoper Parkening Guitar Method, Vol.1 (1997) ini juga ditawarkan latihan untuk bermain bersama/ duet. Latihan ini menarik karena akan terjalin komunikasi antara murid dan guru sehingga murid dapat lebih mudah menangkap proses pembelajarannya karena dia bermain bersama dengan guru. Selain itu, hal menarik adalah guru, instruktur atau ahli juga dituntut untuk aktif bermain bersama dengan murid dalam latihan tangan kanan ini.

Dalam buku Classical Guitar Method dari Bradford Werner (2017) penjelasan yang diberikan sangat singkat dan lebih banyak pada contoh-contoh prakti nya. Selain itu pola latihan yang diberikan bertingkat dari satu senar, dua senar, hingga empat senar.

\section{PENUTUP}

Latihan pada tangan kanan merupakan bagian mendasar dalam belajar gitar klasik karena dalam melatih tangan kanan ini terdapat proses pembentukan menuju posisi yang benar dalam bermain gitar klasik. Kegiatan ini menentukan arah ke depan seorang murid atau peminat gitar klasik dalam mempelajari permainan gitar klasik. Latihan pada tangan kanan ini diawali dengan penjelasan secara teori tentang apa saja yang harus dilakukan murid dari mulai peletakan posisi tangan kanan dan berlanjut pada peletakan posisi jarinya. Dari penjabaran dari ketiga sumber buku tentang metode gitar klasik yang telah dijabarkan pada bagian sebelumnya dapat kita tarik kesimpulan bahwa dalam proses pembelajaran gitar klasik diperlukan proses pembelajaran secara mendasar dimana proses itu memuat nilai penting dalam memainkan dan memahami permainan gitar klasik. Sebagai penutup, penulis memberikan rekomendasi bahwa metode yang telah ditawarkan oleh Classic Guitar Technique dari Aaron Shearer.

\section{DAFTAR PUSTAKA}

Abdulaziz, M., Rahayu, T., \& Rahayu, S. (1). Analisis Isi (Content Analysis) Buku Sekolah Elektronik (BSE) Pelajaran Pendidikan Jasmani Olahraga dan Kesehatan Smp Kelas VIII Di Kota Semarang. Journal of Physical Education and Sports, 3(1). Retrieved from https://journal.unnes.ac.id/sju/index.php/j pes/article/view/4780

Creswell, John W 2010. Research Desain Pendekatan Kualitatif, Kuantitatif, dan Mixed. Yogyakarta: Pustaka pelajar

Fischer, Carl (1946). Carcassi Guitar Method. 65 Bleecker Street, New York, NY 10012

Grossman, R. (1963). The classical guitar: Its place in the American school. Music Educators Journal, 2(3), 140-142.

Grossman, R. (1963). The classical guitar: Its place in the American school. Music Educators Journal, 2(3), 140-142.

Hasbiansyah. (2008). Pendekatan Fenomenologi: Pengantar Praktik Penelitian dalam Ilmu Sosial dan Komunikasi. [Versi Elektronik]. Mediator, Vol 9, No 1

Miftahunnajah, Fadlan. Studi Organologi Pembuatan Gitar Klasik Produksi PT. Genta Trikarya Bandung. Swara Vol 1, No 3 (2013): Antologi Musik Volume 1, No 3 Tahun 2013. Swara

Nabila, A. (2020). Penerapan Teknik Economic Gitar Pada Lagu Tango En Skai Karya Roland Dyens. Virtuoso: Jurnal Pengkajian dan Penciptaan Musik, 1(2), 32-41.

doi:http://dx.doi.org/10.26740/vt.v1n2.p3 2-41

Parkening, C. (1972). The Christopher Parkening guitar method. Vol. 1. A book of basic technique. Chicago: Antique Casa Sherry-Brenner.

Parkening, Christopher (1997) The Christopher Parkening Guitar Method, Vol.1. Hal Leonard Corporation

Salman, F. (2020). Analisis Teknik Permainan Gitar Pada Komposisi Gitar Sunburst Karya Andrew York. Virtuoso: Jurnal Pengkajian dan Penciptaan Musik, 2(2), 99-105.

doi:http://dx.doi.org/10.26740/vt.v2n2.p9 9-105

Sembiring, Adina S (2018) Analisis Bahan Ajar Instrumen Gitar Persiapan Program Studi Pendidikan Musik Universitas Negeri Medan. Gondang: Jurnal Seni dan Budaya, 2 (1) (2018): 1-8

Shearer, Aaron (1963) Classic Guitar Technique, Melville, N.Y. ; St. Leonards, N.S.W. : Franco Colombo Pubs

Shearer, A. (1971). The classic guitar grows up. Music Educators Journal, 58(2), 53, 6465. 
Formula Latihan Teknik Tangan Kanan dalam Gitar Klasik: Shearer, Parkening, dan Werner

Sloane, Irving (1976). Classical Guitar Construction, London, Book Sales Limited, Omnibus Press

Thompson, R Mack (2007) Expressive Gesture In Piano Performance. Master's Thesis Music, Mind \& Technology June 2007 University of Jyväskylä

Werner, Bradford (2017) Classical Guitar Method. thisisclassicalguitar.com 